\title{
Composite Grid and Finite-Volume LU Implicit Scheme for Turbine Flow Analysis
}

Yung K. Choo

Lewis Research Center

Cleveland, Ohio

Seokkwan Yoon

Sverdrup Technology, Inc.

Lewis Research Center

Cleveland, Ohio

and

Kestutis C. Civinskas

Propulsion Directorate

U.S. Army Aviation Research and Technology Activity-AVSCOM

Lewis Research Center

Cleveland, Ohio

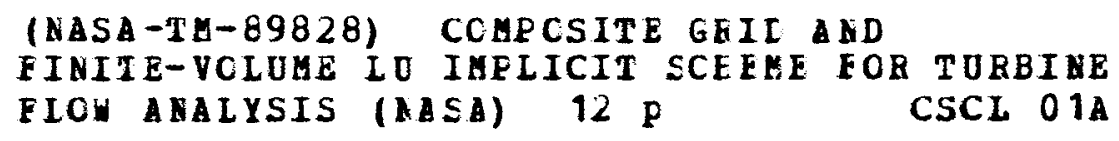

Prepared for the 8th Computational Fluid Dynamics Conference sponsored by the American Institute of Aeronautics and Astronautics Honolulu, Hawaii, June 8-10, 1987 
FOR TURBINE FLOW ANALYSIS

Yung K. Choo*

National Aeronautics and Space Administration

Lewis Research Center

Cleveland, Ohio 44135

Seokkwan Yoon**

Sverdrup Technology, Inc.

Lewis Research Center

Cleveland, Ohio 44135

and

Kestutis C. Civinskast

Propulsion Directorate

U.S. Army Aviation Research and Technology Activity - AvSCOM

Lewis Research Center

Cleveland, Ohio 44135

\section{Abstract}

A composite grid was generated in an attempt to improve grid quality for a typical turbine blade with large camber in terms of mesh control, smoothness, and orthogonality. This composite grid consists of the C-grid (or 0-grid) in the immediate vicinity of the blade and the H-grid in the upstream region and in the middle of the blade passage between the C-grids. It provides a good F boundary layer resolution around the leading-edge if region for viscous calculation, has orthogonality at the blade surface and slope continulty at the $\mathrm{C}-\mathrm{H}$ (or $\mathrm{O}-\mathrm{H}$ ) interface, and has flexibility in controlling the mesh distribution in the upstream region without using excessive grid points. This composite grid eliminates the undesirable qualities of a single grid when generated for a typical turbine geometry.

A finite-volume lower-upper (LU) implicit scheme can be used in solving for the turbine flows on the composite grid. This grid has a special grid node that is connected to more than four neighboring nodes in two dimensions and to more than six nodes in three dimensions. But the fintte-volume approach poses no problem at the special point because each interior cell has only four neighboring cells in two dimensions and only six cells in three dimensions. The finite-volume LU implicit scheme was demonstrated to be robust and efficient for both external and internal flows in a broad flow regime.

\section{Introduction}

Turbine blades are often designed to have substantial thickness and camber and rounded leading and trafling edges. For a typical turbine blade the $\mathrm{H}$-grid does not provide a good boundary layer resolution around the leading edge. If very fine meshes are used to resolve this, the number of grid points in the upstream region becomes excessive. Thus mesh points would be wasted. A turbine flow

\footnotetext{
* Research Scientist, Computational

Applications Branch.

**Senior Research Engineer; Member AIAA.

tAerospace Research Engineer, Computational Applications Branch.
}

analysis on an $\mathrm{H}$-grid indicated that the standard $H$-grid needs cusps at the leading and tralling edges to reach a convergent solution and that it causes somewhat large entropy changes around the leading edge, where the $\mathrm{H}$-grid has a large grid skewness and slope discontinuity. 1 These numerical errors around leading edges would be reduced if a C-grid were used because it provides a better resolution around the leading edge. A standard C-grid was generated for a core turbine stator vane. 2 It reveals large grid skewing on the suction side of the flow passage, which should increase numerical errors.3,4 For a typlcal turbine blade, no single grid offers satisfactory grid properties in the entire turbine stator or rotor passage.

A two-dimensional $\mathrm{O} / \mathrm{H}$ patched grid used in a turbine cascade computation 5 shows the slope discontinuity at the $\mathrm{O}-\mathrm{H}$ grid interface and has extremely large-aspect-ratio meshes near the leading edge. The numerical scheme used in that work is a cell-centered scheme based on the Beam and Warming approximate factorization. 6 Although the flexibility of the scheme is indicated in two dimensions, its likely limitations in three dimensions suggest an alternative approach.

Two- and three-dimensional composite grids were generated in an attempt to improve the grid quality in terms of mesh control, smoothness, and orthogonality. A numerical scheme that will run on this composite grid is discussed.

\section{Composite Grid}

A stator vane ring and the vane geometry at mean section are shown in Figs. $1(a)$ and (b). respectively. This vane ring was used for an annular cascade experiment reported in Ref. 2. To alleviate numerical errors assoctated with the $H$-grid skewness for the blunt leading edge, a standard C-grid (Fig. 2(a)) was generated to examine any possible advantage over the $\mathrm{H}$-grid for this turbine vane geometry. But the grid became very skewed on the suction side of the passage because the blade was highly cambered (Fig. 2(b)). In addition, the control of the mesh distribution in the blade region was 1 imited with the C-grid, because it affected the mesh distribution in the upstream region. Results of numerical simulations 
using this grid are likely to be affected by the grid skewing. 3

Two- and three-dimensional composite grids were generated as shown in Figs. $3(a)$ and (b), respectively. The blades had a constant profile from hub to tip and were stacked at the trailing edge (Fig. $3(\mathrm{C})$ ). Only a selected number of grid lines are shown for illustration. This composite grid consists of the C-grid (or 0 -grid) in the immediate vicinity of the blades and the $\mathrm{H}$-grid in the upstream region and in the middle of the blade passage between the C-grids. The C-grid (or o-grid) portion can be generated by using either the elliptic method ${ }^{7}$ or the algebratc method, 8 At the $\mathrm{C}$-grid and $\mathrm{H}$-grid interface (or $\mathrm{O}-\mathrm{H}$ interface) the slope continuity was preserved so that no special numerical approximations are needed for the derivatives at the interface. The $\mathrm{C}$-grid (or 0 -grid) is orthogonal to the blade surface and provides a good boundary layer resolution near the leading edge. This composite grid has better smoothness and orthogonality and provides more flexibllity in controling the meshes than any single grid for a typical turbine blade with large camber and a rounded leading edge.

The c-grid portion of the composite grid was generated by the elliptic grid generation code. 9 Two subroutines of the code were modified. 10 The outer boundary subroutine was modified, to improve generation of the periodic boundaries, by using the mean camber line for high-solidity blade rows. The inner boundary subroutine was modified to allow a more general clustering of points about the leading and trailing edges of highly cambered turbine blades. Figure 4 illustrates the portion of the $c$-grid between $\eta=0$ and $n=n_{c}$ that was retained for the composite grid. The grid lines at $\eta=0$ and $\eta=\eta_{\max }$ are inner and outer boundaries, respectively. The cholce of $n_{c}$ is arbitrary and may depend on the extent of the shear flow region. The $\eta^{\prime}$ coordinate is a translation of the $n$ coordinate by one pitch in circumferen. tial direction. For the $\mathrm{H}$-grid in the middle between the blades, the $c_{-g}$ id points at $n=n_{c}$ and $n=n_{c+1}$ on the suction side and at $n^{\prime}=n_{c}^{\prime}$ and $n^{\prime}=\eta_{c+1}^{\prime}$ on the pressure side are used in the cubic spline to preserve slope continuity at the $\mathrm{C}-\mathrm{H}$ interface and to effect a smooth change in mesh size. The three-dimensional grid in Fig. 3(b) was constructed algebraically from the composite grids of the hub and shroud surfaces by using the cubic spline and exponential stretching.

A two-dimensional composite grid was also generated for the first-stage stator and rotor of the space shuttle main engine (SSME) fuel-turbopump tur. bine. Figure 5 shows the construction of the $\mathrm{C}-\mathrm{H}$ composite grid for the rotor blade. Figure 6 shows the composite grid generated for the stator vane. one merit of the composite grid is the flexibility in constructing the $\mathrm{H}$-grid in the upstream region. One can choose the number and distribution of meshes, and the H-grid can be extended in the upstream direction independently of the C-grid part of the composite grid around the blade. With this flexibility the downstream end of the grid for the stator can easily be matched with the upstream end of the grid for the rotor in the vaneless space between the stator and rotor. Figure 7 1llustrates that the composite grid can be easily constructed for a stator/rotor interaction study.
Numerical Scheme

\section{Semidiscrete Finite-Volume Scheme}

The two-dimensional $\mathrm{C}-\mathrm{H}$ composite grid has an unusual grid point that is connected to more than four neighboring nodes (Fig. 8(a)). At this point the usual differencing techniques cannot be applied. If a standard finite-difference scheme were used to solve a flow problem on this composite grid, it would be difficult to treat this special point. A finite-volume schemell to be used with this composite grid presents no problem and requires no special treatment because each interior cell of this composite grid has only four neighboring cells in two dimensions and six neighboring cells in three dimensions (Fig. 8(b)). The finite-volume scheme is described briefly here.

The Euler equations in integral form can be written as

$$
\frac{\partial}{\partial t} \iiint_{\Omega} w d \Omega+\iint_{\partial \Omega} \underline{F} \cdot d \underline{S}=0
$$

for a fixed region $\Omega$ with boundary $a \Omega$. Here $w$ represents the conserved quantity, $F$ is the corresponding flux term, and $t$ is time.

A convenient way to ensure a steady-state solution independent of the time step is to separate the space and time discretization procedures. In the semidiscrete finite-volume scheme one begins by applying a semidiscretization in which only the spatial derivatives are approximated. To derive a semidiscrete model that can be used to treat complex geometric domains, the computational domain is divided into quadrilateral cells. Assuming that the dependent variables are known at the center of each cell, a system of ordinary differential equations is obtained by applying equation (1) separately to each cell. These equations have the form

$$
\frac{d}{d t}\left(S_{i j} w_{i j}\right)+Q_{1 j}=0
$$

where $S_{i j}$ is the cell area and $Q_{1 j}$ is the net flux out of the cell. This can be evaluated as

$$
\sum_{k=1}^{4}\left(\Delta y_{k} f_{k}-\Delta x_{k} g_{k}\right)
$$

where $f_{k}$ and $g_{k}$ denote values of the flux vectors $f$ and $g$ on the $k$ th edge, $\Delta x_{k}$ and $\Delta y_{k}$ are the increments of $x$ and $y$ along the edge with appropriate signs, and the sum is over the four sides of the cell. The flux vectors are evaluated, for example, by averaging the values in the cells on either side of the edge:

$$
f_{1}=\frac{1}{2}\left(f_{i+1, j}+f_{i, j}\right)
$$

The scheme constructed in this manner reduces to a central-difference scheme on a Cartesian grid and is second-order accurate in space provided that the mesh is smooth enough. It also has the property that uniform flow is an exact solution of the difference equations.

\section{LU Implicit Scheme}

The composite grid is generated to be used for both inviscid and viscous flow calculations. For 
viscous calculations the $\mathrm{C}$ - or 0 -meshes must be very fine to resolve the boundary layer. And it is likely that the time step imposed by an explicit stability bound will be much less than that imposed by the accuracy bound of an implicit scheme. Since an obvious way to accelerate convergence to a steady state is to increase the size of the time step, an implicit scheme is expected to have a faster convergence. Although the alternating direction implicit (ADI) scheme has been valuable in two-dimensional problems, its inherent limitations in three dimensions suggest an alternative approach. An LU implicit scheme was demonstrated to be efficient and robust for both external and internal flows in a broad flow regime.12-14 The scheme was extended for three-dimensional flows on an H-grid. 15 This scheme will be used for the numerical simulation of turbine flows on the composite grid.

The conservation law form of the Euler equations in Cartesian coordinates for two-dimensional flow is

$$
\frac{\partial \underline{W}}{\partial t}+\frac{\partial \underline{F}}{\partial x}+\frac{\partial \underline{G}}{\partial y}=0
$$

where $W$ is the vector of dependent variables and $E$ and $G$ are convective flux vectors:

$$
\begin{gathered}
\underline{W}=(\rho, \rho u, \rho v, \rho E)^{\top} \\
\underline{F}=\left[\rho u, \rho u^{2}+p, \rho v u, u(\rho E+p)\right]^{T} \\
\underline{G}=\left[\rho v, \rho u v, \rho v^{2}+p, v(\rho E+p)\right]^{\top}
\end{gathered}
$$

where $\rho, u, v, E$, and $p$ are density, velocity components, total energy, and pressure. The pressure is abtained from the equation of state

$$
p=\rho(\gamma-1)\left[E-\frac{1}{2}\left(u^{2}+v^{2}\right)\right]
$$

where $\gamma$ is the ratio of specific heats. These equations are to be solved for a steady-state $\partial W / \partial t=0$, where $t$ denotes time.

Let the Jacobian matrices be

$$
A=\frac{\partial \underline{F}}{\partial \underline{W}}, \quad B=\frac{\partial \underline{G}}{\partial \underline{W}}
$$

and let the correction be

$$
\delta \underline{w}=\underline{w}^{n+1}-\underline{w}^{n}
$$

where $n$ denotes the time level.

The linearized implicit scheme for a system of nonlinear hyperbolic equations such as the Euler equations can be formulated as

$$
\left[I+B \Delta t\left(D_{x} A+D_{y} B\right)\right] \delta \underline{W}+\Delta t \underline{R}=0
$$

where $I$ is the identity matrix and $\underline{R}$ is the residual

$$
\underline{R}=D_{x} \underline{F}\left(\underline{W}^{n}\right)+D_{y} \underline{G}\left(\underline{W}^{n}\right)
$$

Here $D_{x}$ and $D_{y}$ are central difference operators that approximate $\partial / \partial x$ and $\partial / \partial y$.

If $\beta=1 / 2$, the scheme remains second-order accurate in time; for other values of $B$ the time accuracy drops to first order. The unfactored implicit scheme (eq. (7)) produces a large blockbanded matrix, which is very costly to invert and requires huge storage. An unconditionally stable implicit scheme that has error terms at most of order $(\Delta t)^{2}$ in any number of space dimensions can be derived by LU factorization

$$
\begin{gathered}
{\left[I+B \Delta t\left(D_{x}^{-} A^{+}+D_{y}^{-} B^{+}\right)\right]\left[I+\beta \Delta t\left(D_{x}^{+} A^{-}+O_{y}^{+} B^{-}\right)\right]} \\
x \delta \underline{W}+\Delta t R=0 .
\end{gathered}
$$

where $D_{\bar{x}}^{-}$and $D_{\bar{y}}^{-}$are backward difference operators and $D_{x}^{+}$and $D_{y}^{+}$are forward difference operators. The reason for splitting is to ensure the diagonal dominance of lower and upper factors as well as to make use of the built-in implicit dissipation.

Here $A^{+}, A^{-}, B^{+}$, and $B^{-}$are constructed so that the eigenvalues of " + " matrices are nonnegative and those of "-" matrices are nonpositive.

$$
\begin{aligned}
A^{+} & =\frac{1}{2}\left(A+r_{A} I\right), & A^{-} & =\frac{1}{2}\left(A-r_{A} I\right) \\
B^{+} & =\frac{1}{2}\left(B+r_{B} 1\right), & B^{-} & =\frac{1}{2}\left(B-r_{B} I\right)
\end{aligned}
$$

where

$$
r_{A} \geq \max \left(\left|\lambda_{A}\right|\right), \quad r_{B} \geq \max \left(\left|\lambda_{B}\right|\right)
$$

Here $\lambda_{A}$ and $\lambda_{B}$ represent eigenvalues of Jacobian matrices. Equation ( 8 ) can be inverted in two steps. The LU implicit scheme needs the inversion of sparse triangular matrices, which can be done efficiently without using large storage. This scheme has only two factors in three dimensions.

\section{Concluding Remarks}

Two- and three-dimensional composite grids were generated to improve grid quality for an annular turbine cascade in terms of smoothness, resolution, and orthogonality. This composite grid, which has a C-type (or 0-type) grid in the immediate vicinity of the turbine blade, provides a good boundary layer resolution around the leading-edge region for viscous calculation, has orthogonality at the blade surface and slope continuity at the $\mathrm{C}-\mathrm{H}$ (or $\mathrm{O}-\mathrm{H}$ ) interface, and controls the mesh distribution in the upstream region without using excessive grid points. This composite grid eliminates the undesirable qualities of a single grid when generated for a typical turbine geometry.

The $\mathrm{C}-\mathrm{H}$ composite grid has flexibility in constructing the $\mathrm{H}$-grid in the upstream region so that the grids for the stator vanes and rotor blades of the SSME fuel-turbopump turbine can easily be matched in the vaneless space and can be used for the stator-rotor interaction study.

A finite-volume lower-upper (LU) implicit scheme is to be used in solving the turbine flows on the composite grid. This grid has a special grid node that is connected to more than four neighboring nodes in two dimensions and to more than six nodes in three dimensions. But the finite-volume approach poses no problem at the special point because each interior cell has only four neighboring cells in two dimensions and only 
six cells in three dimensions. The finite-volume LU implicit scheme was proven to be robust and efficlent in a broad flow regime and is expected to yield accurate solutions on the improved composite grid.

\section{References}

1. Choo, Y.K. and Civinskas, K.C., "ThreeDimensional Inviscid Analysis of Radial-Turbine Flow and a Limited Comparison with Experimental Data," Three-Dimensional Flow Phenomena in Flutd Machinery, A. Hamed, J. Herring, and L. Povinelli, Eds., ASME, New York, 1985, pp. $181-190$.

2. Goldman, L.J. and Seasholtz, R.G., "Laser Anemometer Measurements in an Annular Cascade of Core Turbine vanes and Comparison with Theory," NASA 1P-2018, 1982.

3. Steger, J.L., "On Application of Body Conforming Curvilinear Grids for Finite Difference Solution of External Flow," Numerical Grid Generation. J.F. Thompson, Ed., North-Holland, New York, 1982 , pp. $295-316$.

4. Davis, R.L., Ni, R.H., and Carter, J.E., "Cascade Viscous Flow Analys is Using the NavierStokes Equations," AIAA Paper 86-0033, Jan. 1986.

5. Norton, R.J.G., Thompkins, W.T., Jr., and Haimes, R., "Implicit Finite-Difference Schemes with Non-Simply-Connected Grids - A Nove1 Approach," AIAA Paper 84-0003, Jan. 1984.

6. Beam, R.M. and Warming, R.F., "An Implicit Factored Scheme for the Compressible NavierStokes Equations," AIAA Journal, Vol. 16, No. 4, Apr. 1978, pp. 393-402.

7. Thompson, J.F., Thames, F.C., and Mastin, C.W., "Automatic Numerical Generation of Body-fitted Curvilinear Coordinate System for Field Containing Any Number of Arbitrary Two- Dimensional Bodies, "Journal of Computational Physics, Vol. 15, No. 3, July 1974 , pp. 299-319.
8. Eiseman, P.R. and Smith, R.E., "Mesh Generation Using Algebraic Techniques," Numerical Grid Generation Techniques. NASA CP-2166, 1980, pp. 73-120.

9. Sorenson, R.L., "A Computer Program to Generate Two-Dimensional Grids About Airfoils and Other Shapes by the Use of Poisson's Equation," NASA TM-81198, 1980.

10. Chima, R.V., "Analysis of Inviscid and Viscous Flows in Cascades with an Explicit Multiple-Grid Algorithm," NASA TM-83636, 1984.

11. Jameson, A. and Yoon, S., "Multigrid Solution of the Euler Equations Using Implicit Schemes," AIAA Journal, Vol. 24, No. 11, Nov. 1986, pp. 1737-1743.

12. Jameson, A. and Yoon, S., "LU Implicit Schemes with Multiple Grids for the Euler Equations," AIAA Paper 86-0105, Jan. 1986.

13. Yoon, S. and Jameson, A., "An LU Implicit Scheme for High Speed Inlet Analysis," AIAA Paper 86-1520, June 1986.

14. Yoon, S. and Jameson, A., "A High Resolution Shock Capturing Scheme for High Mach Number Internal Flow," NASA CR-179523, 1986.

15. Yokota, J.W. and Caughey, D.A., "An L-U Implicit Multigrid Algorithm for the ThreeDimensional Euler Equations," AIAA Paper 87-0453, Jan. 1987 

ORIGINAL PACE IS

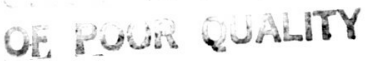

\section{OF POOR QUALITY}

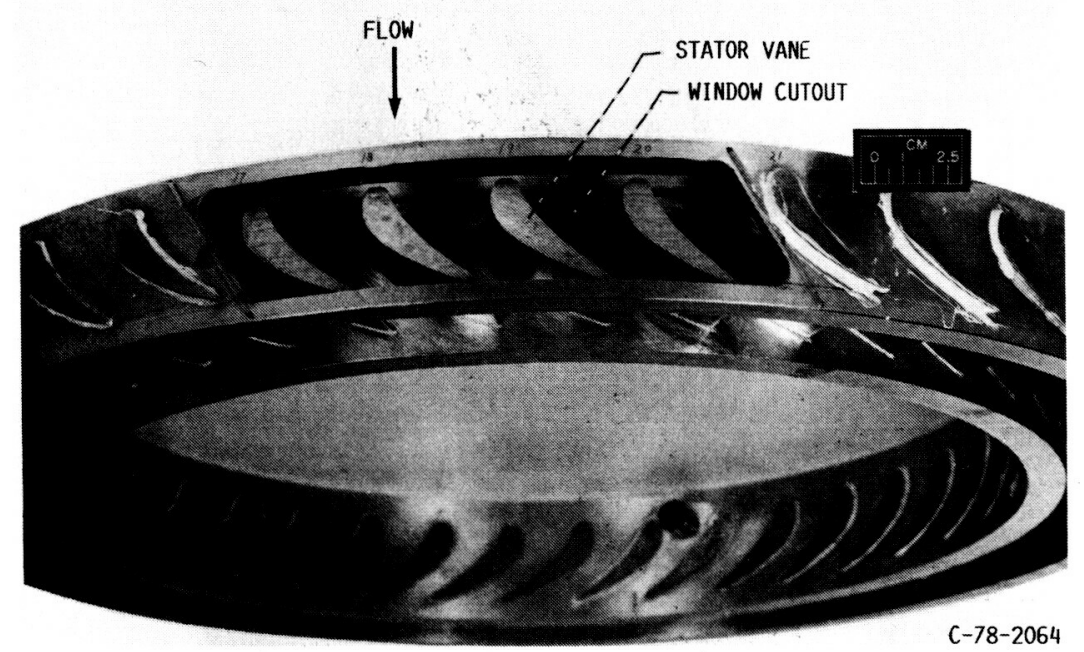

(A) RING SHOWING CUTOUT FOR LASER WINDOW.

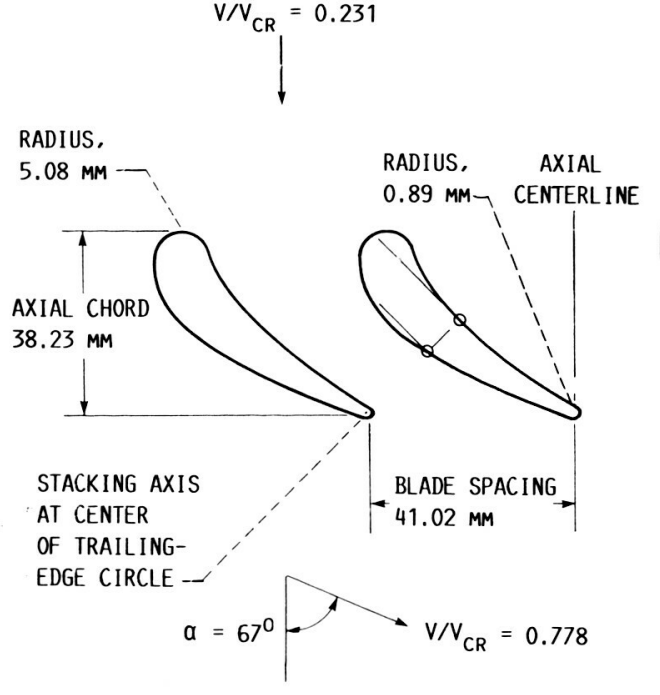

(B) GEOMETRY AT MEAN SECTION. ( $\mathrm{V} / \mathrm{V}_{\mathrm{CR}}=$ CRITICAL VELOCITY RATIO.)

FIGURE 1. - CORE TURBINE STATOR VANE.

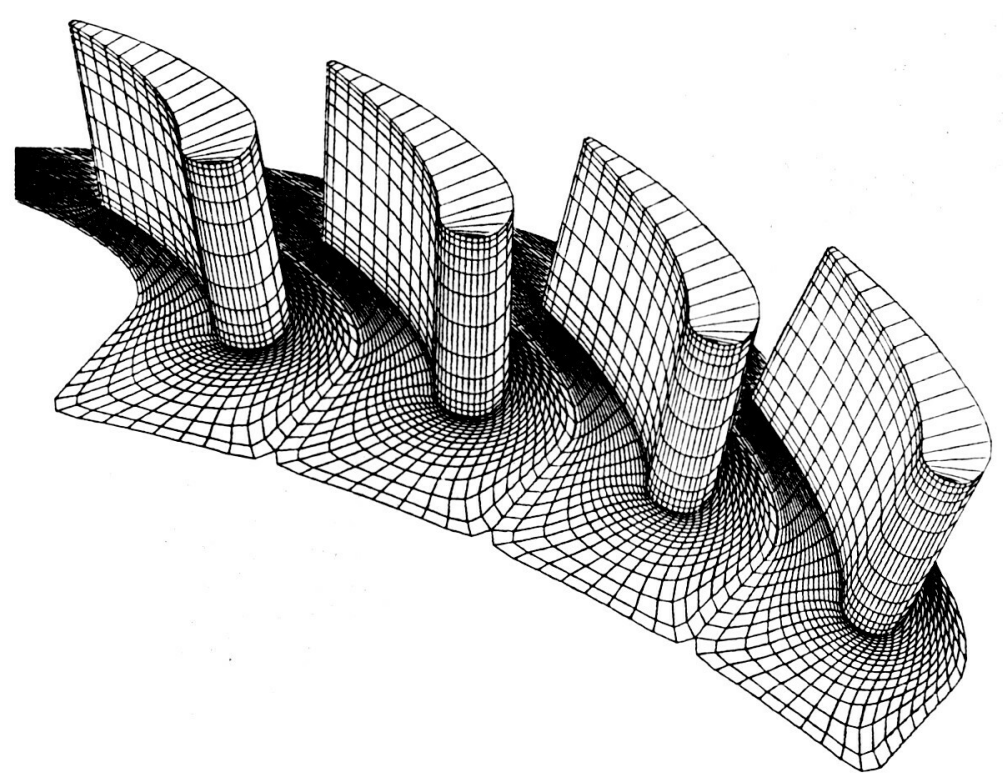

(A) THREE DIMENSIONS.

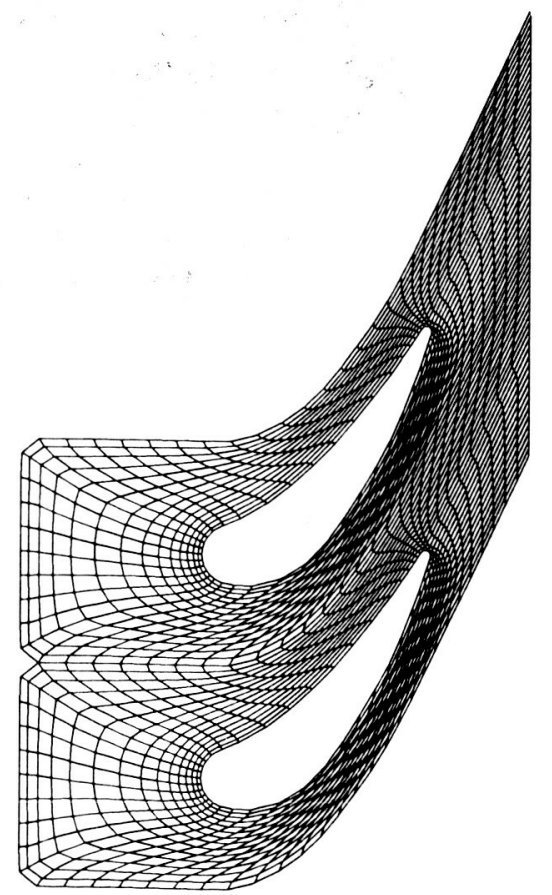

(B) TWO DIMENSIONS

FIGURE 2. - STANDARD C-GRID FOR CORE TURBINE VANES. 


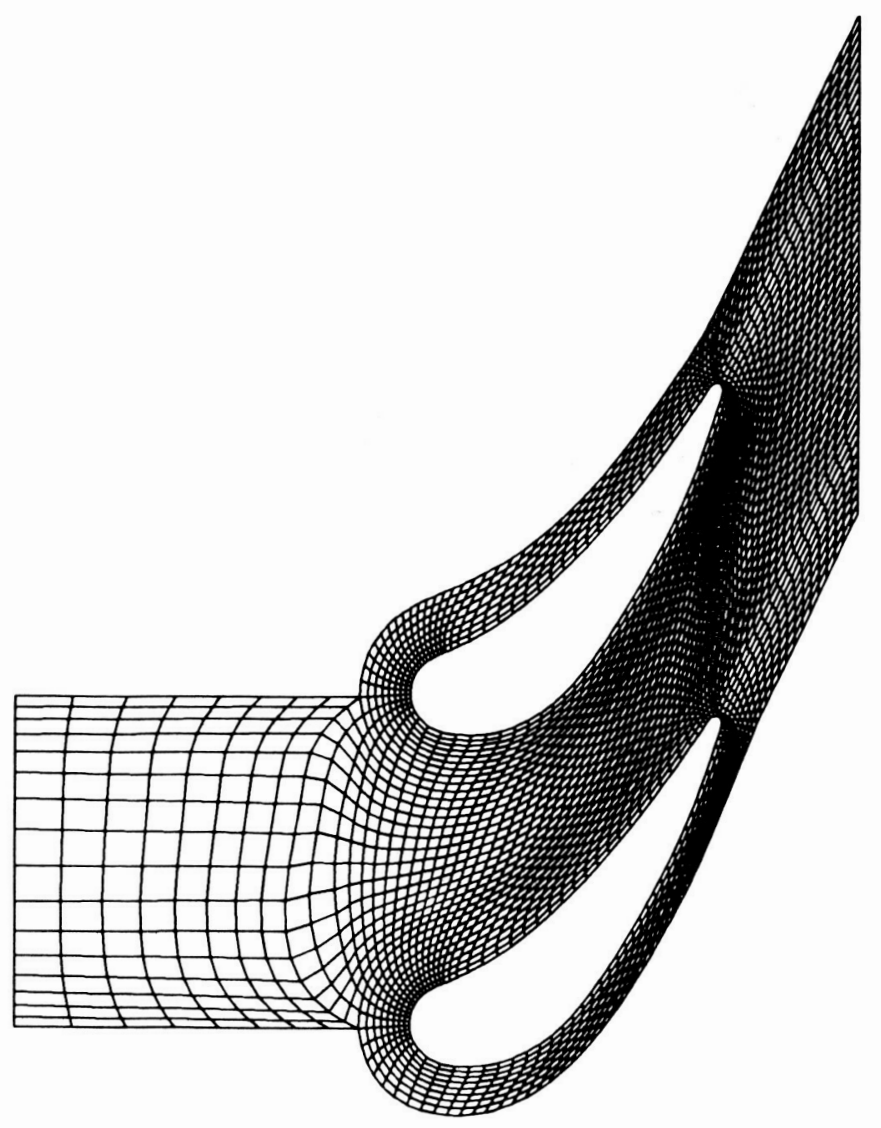

(A) TWO DIMENSIONS.

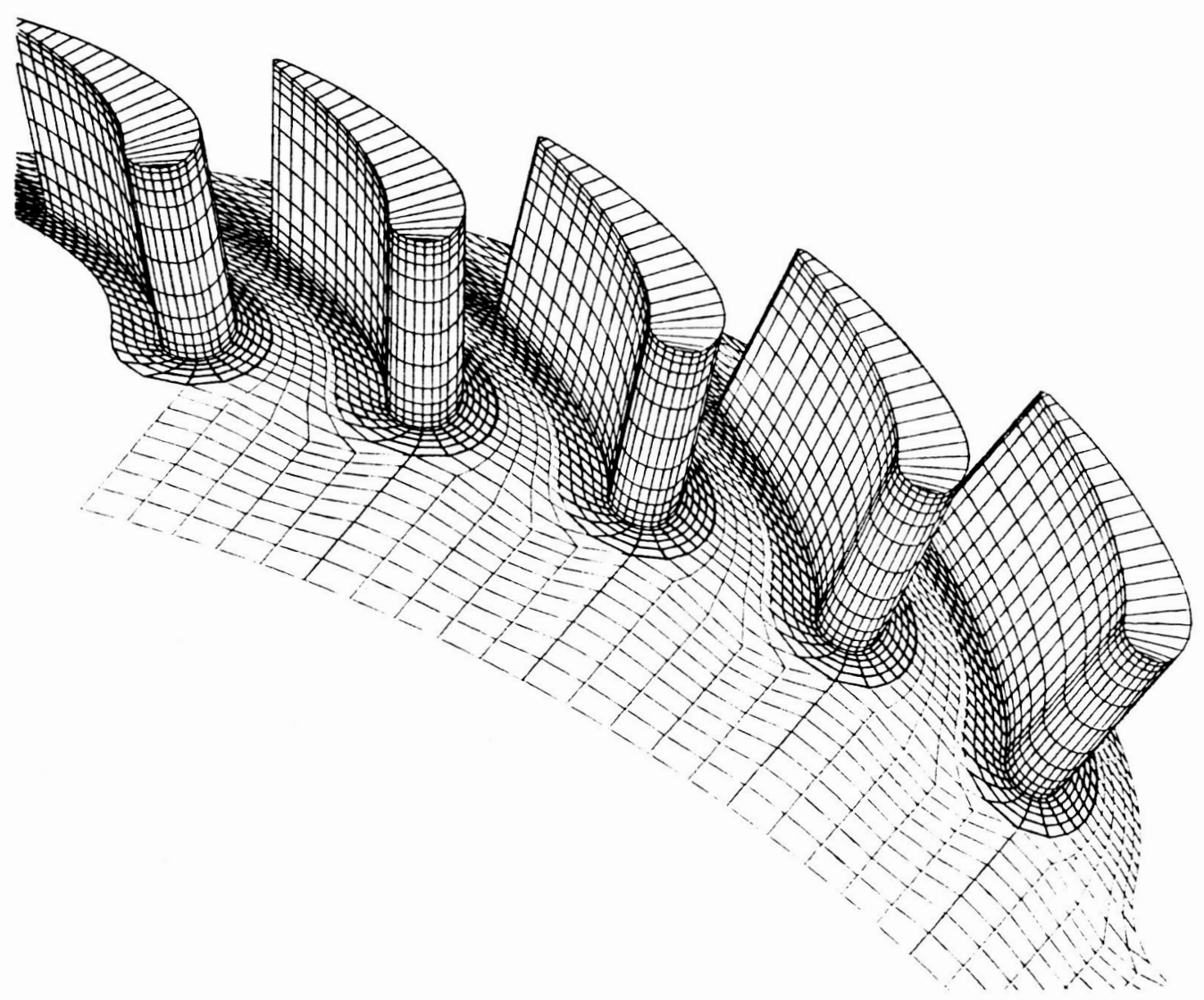

(B) THREE DIMENSIONS.

FIGURE 3. - COMPOSITE GRID FOR CORE TURBINE STATOR VANES. 


\section{ORIGINAL PAGE IS \\ OF. POOR QUALITY}

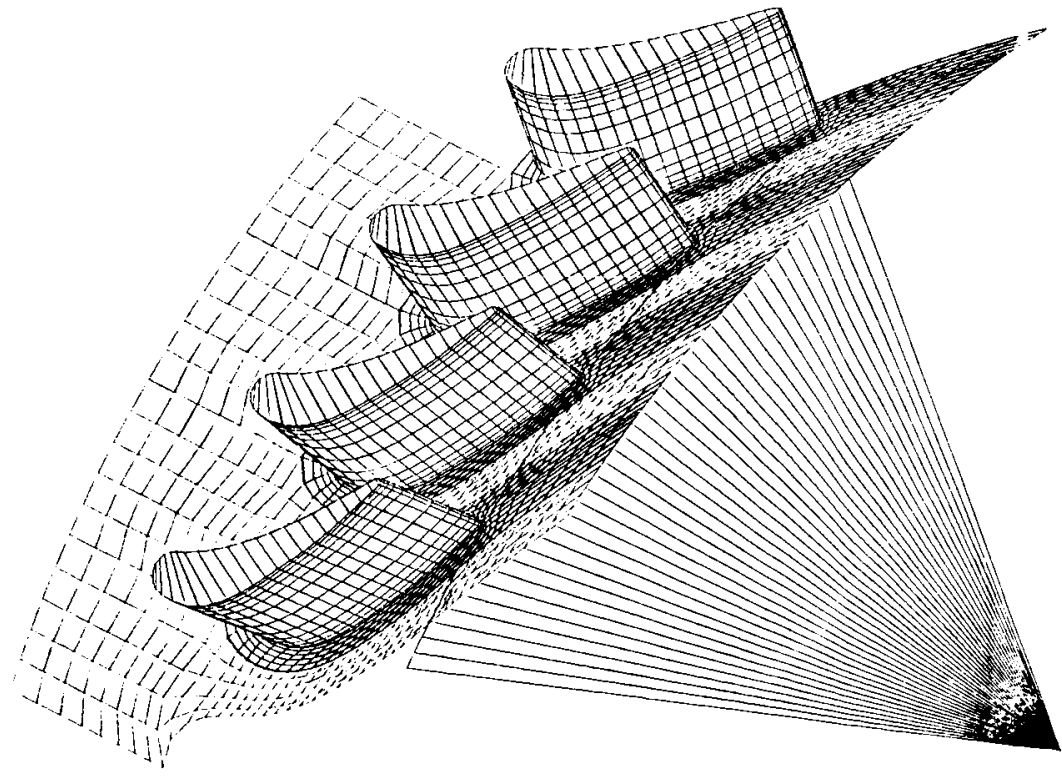

(C) STACKED AT TRAILING EDGES.

FIGURE 3. - CONCLUDED.

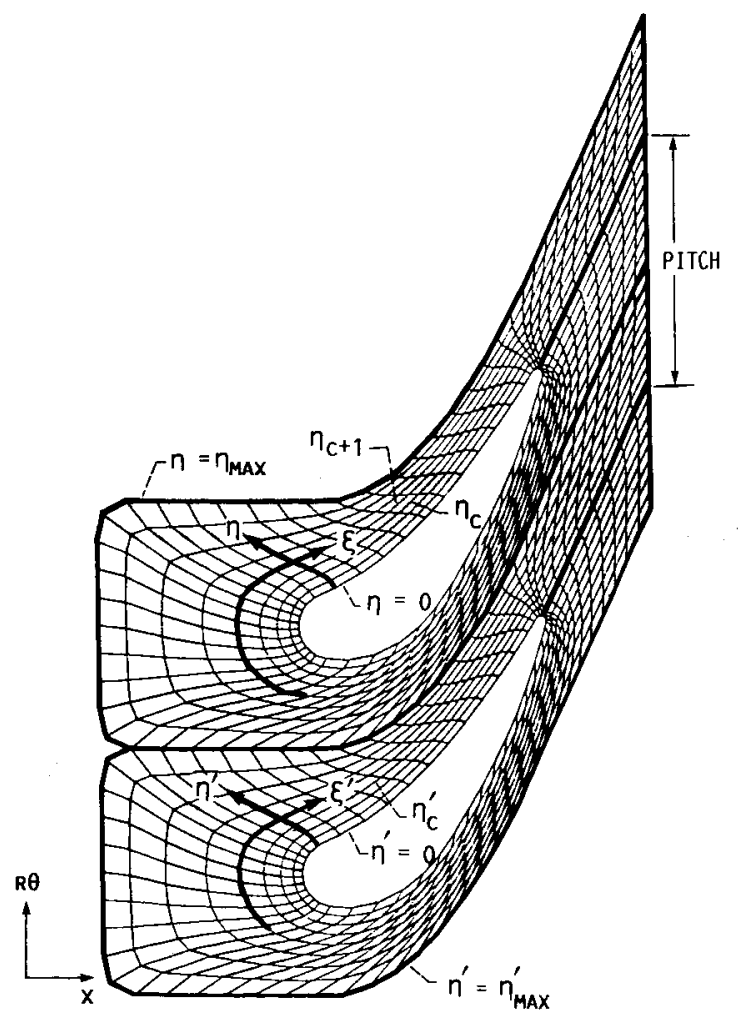

FIGURE 4. - STANDARD TWO-DIMENSIONAL C-GRID FOR CORE TURBINE VANES WITH BODY-FITTED COORDINATES SHOWN.

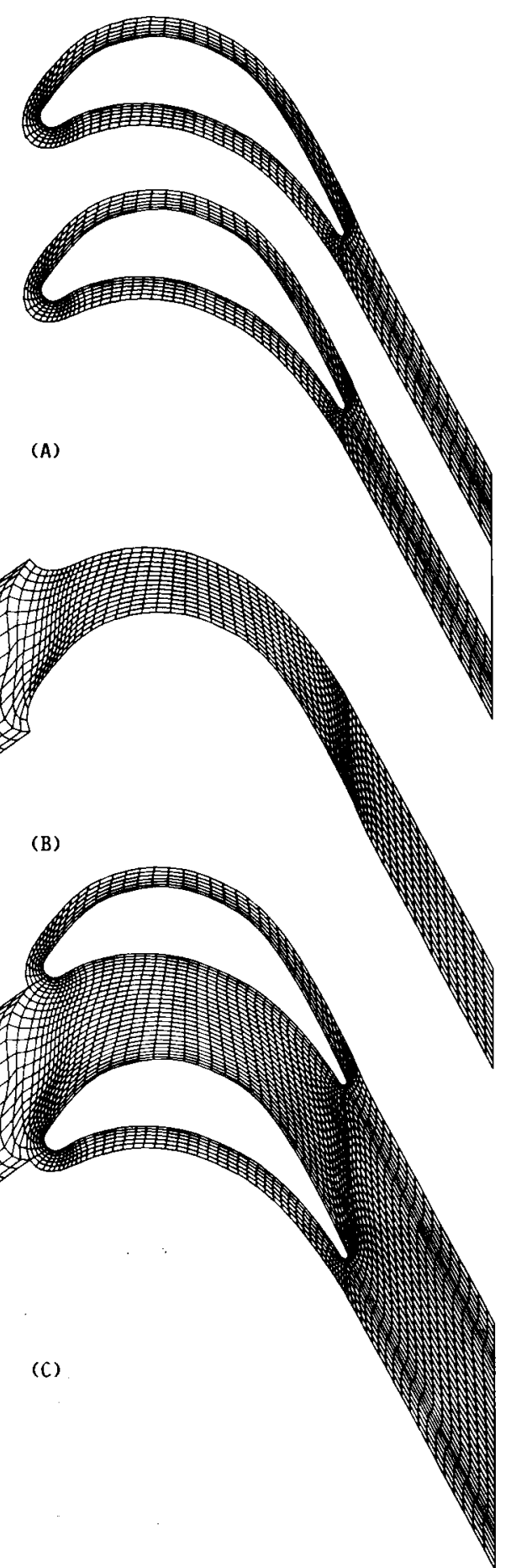

(A) C-GRID IN IMMEDIATE VICINITY OF ROTOR BLADE.

(B) PATCHING OF GRID IN BLADE REGION AND EXTENSION OF H-GRID INTO UPSTREAM REGION.

(C) COMPOSITE GRID.

FIGURE 5. - CONSTRUCTION OF C-H COMPOSITE GRID FOR FIRSTSTAGE ROTOR OF SSME FUEL-TURBOPUMP TURBINE. 


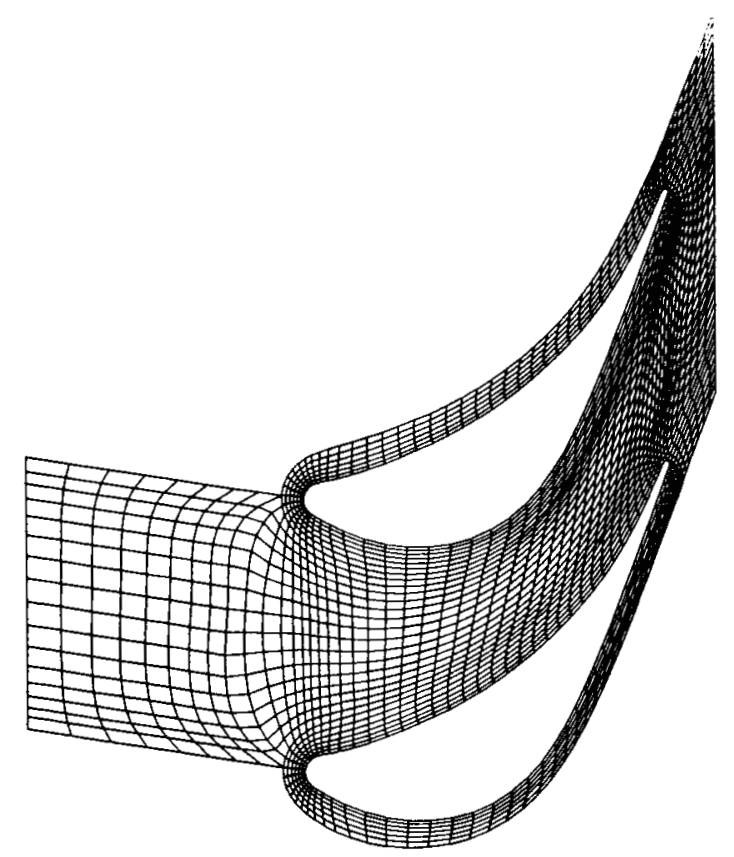

FIGURE 6. - COMPOSITE GRID FOR FIRST-STAGE STATOR OF SSME FUEL-TURBOPUMP TURBINE.

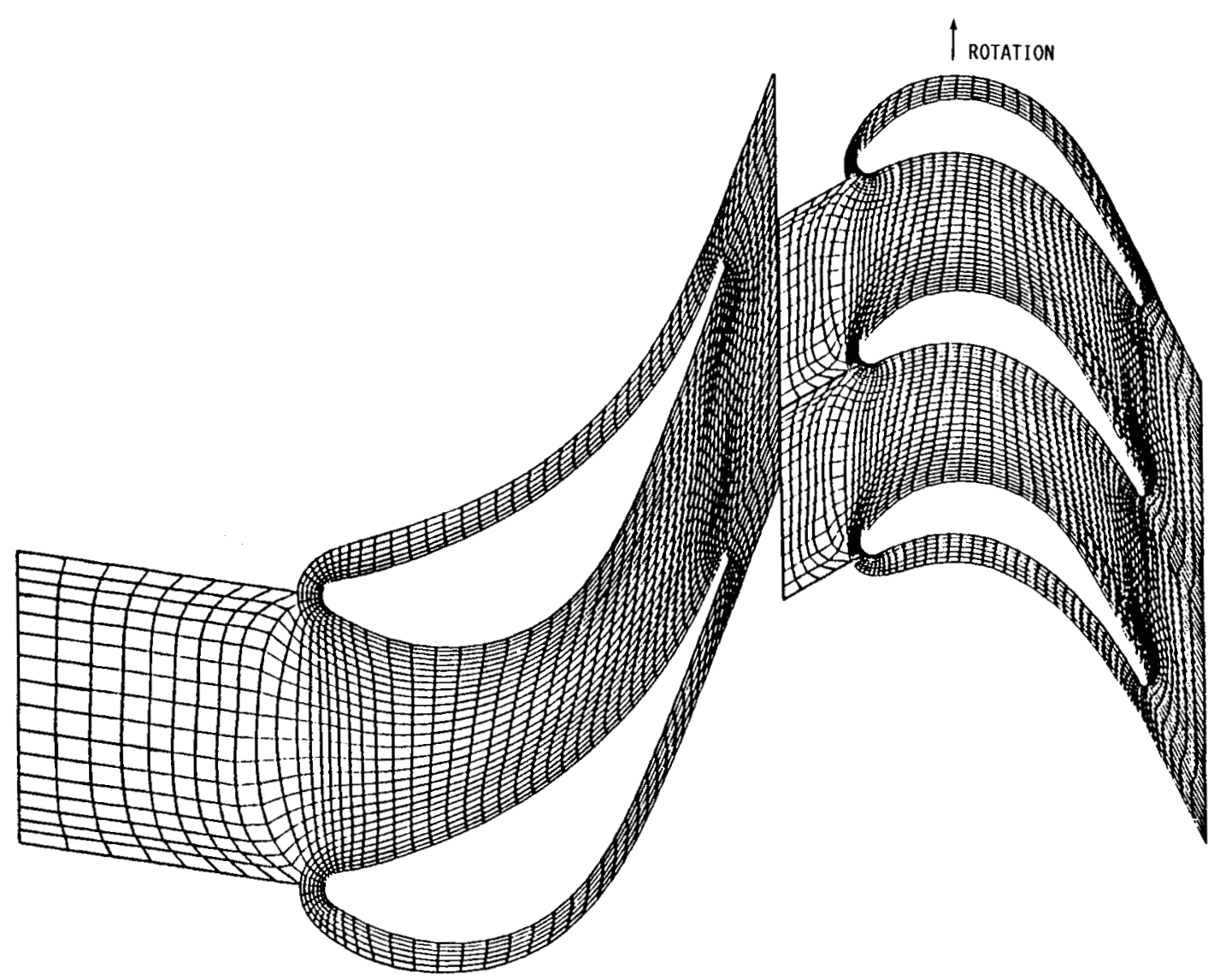

FIGURE 7. - COMPOSITE GRID FOR FIRST STAGE OF SSME FUEL-TURBOPUMP TURBINE. 


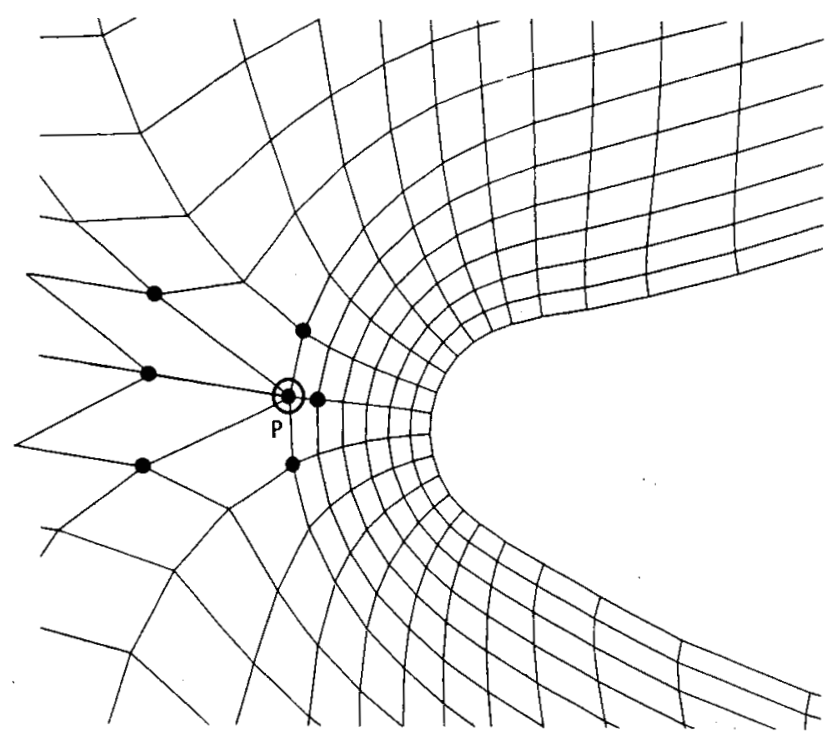

(A) GRID NODES TO BE USED IN FINITE-DIFFERENCE SCHEME.

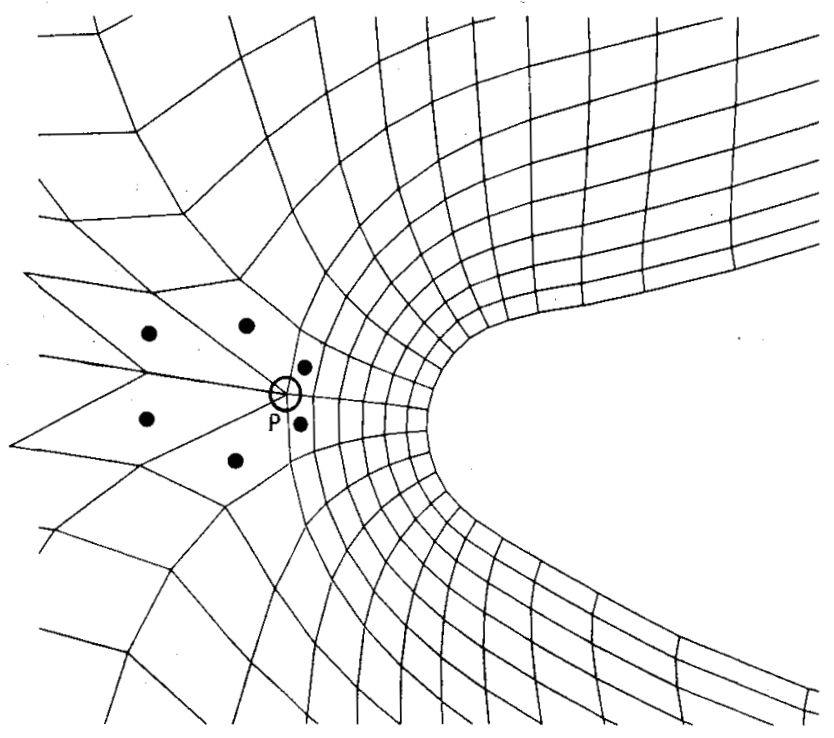

(B) CELL CENTERS TO BE USED IN FINITE-VOLUME SCHEME. FIGURE 8. - SPECIAL POINT (P) OF COMPOSITE GRID. 


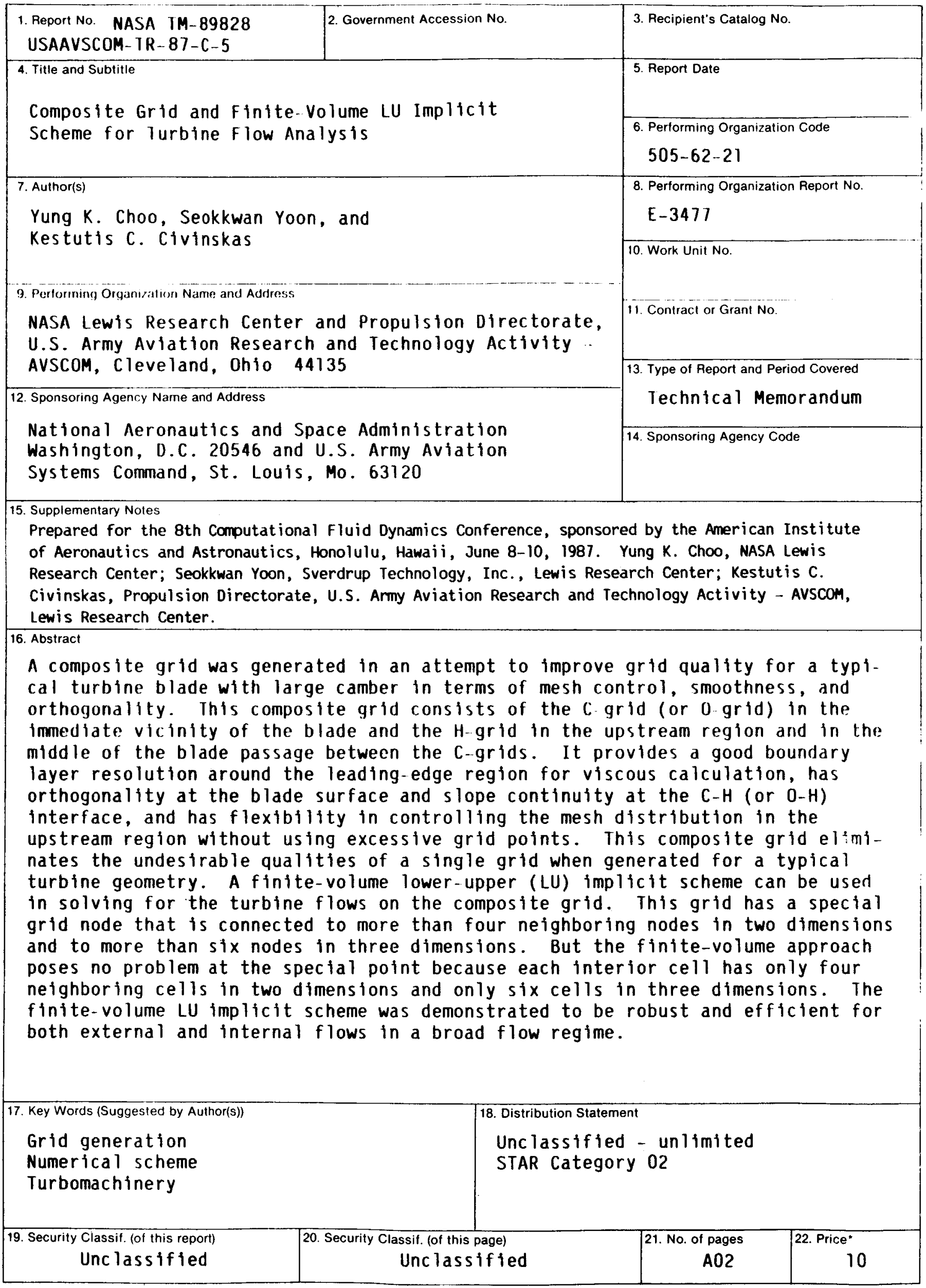

"For sale by the National Technical Information Service, Springfield, Virginia 22161 